\title{
Cryptosporidium parvum, a potential cause of colic adenocarcinoma
} Gabriela Certad ${ }^{* \dagger 1,2}$, Tramy Ngouanesavanh ${ }^{\dagger 1}$, Karine Guyot ${ }^{1}$, Nausicaa Gantois ${ }^{1}$, Thierry Chassat ${ }^{3}$, Anthony Mouray ${ }^{3}$, Laurence Fleurisse ${ }^{4}$, Anthony Pinon ${ }^{5}$, Jean-Charles Cailliez ${ }^{6}$, Eduardo Dei-Cas ${ }^{1,7}$ and Colette Creusy ${ }^{4}$

\author{
Address: ${ }^{1}$ Ecologie du Parasitisme (EA3609 Université de Lille 2), IFR 142, Institut Pasteur de Lille, Lille, France, ${ }^{2}$ Cátedra de Parasitología, Escuela \\ de Medicina "José María Vargas", Universidad Central de Venezuela (UCV), Caracas, Venezuela, ${ }^{3}$ Plateau d'Expérimentation Animale, Institut \\ Pasteur de Lille, France, ${ }^{4}$ Service d'Anatomie et de Cytologie Pathologiques, Groupe Hospitalier de l'Université Catholique de Lille, France, ${ }^{5}$ Unité \\ de Sécurité Microbiologique, Institut Pasteur de Lille, France, ${ }^{6}$ Laboratoire Environnement et Santé, Université Catholique de Lille, France and \\ ${ }^{7}$ Parasitologie-Mycologie, Centre Hospitalier Régional et Universitaire de Lille, Université de Lille 2, France \\ Email: Gabriela Certad* - gabriela.certad@pasteur-lille.fr; Tramy Ngouanesavanh - ndn.tramy@gmail.com; \\ Karine Guyot - karine.guyot@pasteur-lille.fr; Nausicaa Gantois - nausicaa.gantois@pasteur-lille.fr; Thierry Chassat - thierry.chassat@pasteur- \\ lille.fr; Anthony Mouray - anthony.mouray@pasteur-lille.fr; Laurence Fleurisse - lfleurisse@yahoo.fr; Anthony Pinon - anthony.pinon@pasteur- \\ lille.fr; Jean-Charles Cailliez - jean-charles.cailliez@icl-lille.fr; Eduardo Dei-Cas - eduardo.dei-cas@pasteur-lille.fr; \\ Colette Creusy - ccreusy@nordnet.fr \\ * Corresponding author †Equal contributors
}

Published: 21 November 2007

Infectious Agents and Cancer 2007, 2:22 doi:10.1 186/1750-9378-2-22
Received: 2 July 2007

Accepted: 21 November 2007

This article is available from: http://www.infectagentscancer.com/content/2/I/22

(c) 2007 Certad et al; licensee BioMed Central Ltd.

This is an Open Access article distributed under the terms of the Creative Commons Attribution License (http://creativecommons.org/licenses/by/2.0), which permits unrestricted use, distribution, and reproduction in any medium, provided the original work is properly cited.

\begin{abstract}
Background: Cryptosporidiosis represents a major public health problem. This infection has been reported worldwide as a frequent cause of diarrhoea. Particularly, it remains a clinically significant opportunistic infection among immunocompromised patients, causing potentially life-threatening diarrhoea in HIV-infected persons. However, the understanding about different aspects of this infection such as invasion, transmission and pathogenesis is problematic. Additionally, it has been difficult to find suitable animal models for propagation of this parasite. Efforts are needed to develop reproducible animal models allowing both the routine passage of different species and approaching unclear aspects of Cryptosporidium infection, especially in the pathophysiology field.

Results: We developed a model using adult severe combined immunodeficiency (SCID) mice inoculated with Cryptosporidium parvum or Cryptosporidium muris while treated or not with Dexamethasone (Dex) in order to investigate divergences in prepatent period, oocyst shedding or clinical and histopathological manifestations. C. muris-infected mice showed high levels of oocysts excretion, whatever the chemical immunosuppression status. Pre-patent periods were II days and 9.7 days in average in Dex treated and untreated mice, respectively. Parasite infection was restricted to the stomach, and had a clear preferential colonization for fundic area in both groups. Among C. parvum-infected mice, Dex-treated SCID mice became chronic shedders with a prepatent period of 6.2 days in average. C. parvum-inoculated mice treated with Dex developed glandular cystic polyps with areas of intraepithelial neoplasia, and also with the presence of intramucosal adenocarcinoma.

Conclusion: For the first time $C$. parvum is associated with the formation of polyps and adenocarcinoma lesions in the gut of Dex-treated SCID mice. Additionally, we have developed a model to compare chronic muris and parvum cryptosporidiosis using SCID mice treated with corticoids. This reproducible model has facilitated the evaluation of clinical signs, oocyst shedding, location of the infection, pathogenicity, and histopathological changes in the gastrointestinal tract, indicating divergent effects of Dex according to Cryptosporidium species causing infection.
\end{abstract}




\section{Background}

Cryptosporidiosis represents a major public health problem. This infection, caused by protozoa of the genus Cryptosporidium, has been reported worldwide as a frequent cause of diarrhoea, and its prevalence varies according to different regions [1]. In developed countries, massive Cryptosporidium foodborne and waterborne outbreaks have been reported. In developing countries, Cryptosporidium affects mostly children under five [2]. Furthermore, cryptosporidiosis remains a clinically significant opportunistic infection in immunocompromised patients, causing potentially life-threatening diarrhoea, especially in those HIV-infected without access to highly active antiretroviral therapy (HAART) [3]. Additionally, these parasites not only infect humans, but also cause morbidity in farm animals, leading to economic losses [4]. Most Cryptosporidium species infect the epithelium of the gut but in severe infections, dissemination can occur to extra-intestinal sites [5]. Infection of the intestinal cells can result in blunting of the intestinal villi, crypt hyperplasia and inflammation. Epithelial cell apoptosis due to this parasite has also been described $[6,7]$.

Molecular techniques have been developed to differentiate this parasite at the species and genotype levels, showing that there are at least 16 different species [1], and several methods have been used to study and characterize different parasite strains. However, the understanding about invasion, transmission, pathogenesis and epidemiology is limited, and no effective drug against this infection is available. Previous studies based on multilocus characterisation of Cryptosporidium isolates identified different sub-groups within some Cryptosporidium species [811]. These groups exhibited different population genetic structures (epidemic clonality and panmixia) that could be correlated to defined phenotypes.

To contribute to the comprehension of the dynamics of infection and to investigate biological divergence between different populations of Cryptosporidium, tissue culture and animal models have been used. It has been difficult to find suitable models for cryptosporidiosis, as most mammalians are susceptible to infection only as newborns [12]. However, some Cryptosporidium species can be propagated in either chemically or genetically immunosuppressed mice. Particularly, adult mice with congenital mutations such as $n u / n u, s c i d, b g / n u, x i d$ or mice with steroid induced immunosuppression are susceptible to infection [12-17]. Efforts are still needed to develop reproducible animal models allowing both the routine passage of different species and approaching unclear aspects of Cryptosporidium infection, especially in the pathophysiology field.
We have developed a model to compare chronic muris and parvum cryptosporidiosis using SCID mice treated with corticoids in order to evaluate clinical signs, location of the infection, pathogenicity, oocyst shedding and histopathological changes in the gastrointestinal tract. This model was chosen for the following reasons: i) Previous studies have shown that host cell immunity during cryptosporidiosis is mediated by both Th1 and Th2 response $[18,19]$, thus SCID mice are more susceptible to the infection and to develop a chronic disease due to their defect in $\mathrm{T}$ and B lymphocytes [20]. ii) It has been found that during cryptosporidiosis there is an IFN $\gamma$ mucosal response with increased levels of Il15 [21]. IFN $\gamma$-induced enterocyte resistance against $C$. parvum has been reported [22]. Furthermore, glucocorticoids are known to have an effect on the priming of the innate immune response [23], and could suppress IFN $\gamma$-regulated gene expression [24]. Consequently, dexamethasone, a synthetic glucocorticosteroid, could be used to alter this innate immune response. iii) This model of SCID mice treated with steroids has been proven to be successful for the development of Pneumocystis, another opportunistic agent [25].

\section{Results}

The pathological damage due to C. muris or C. parvum infection was studied in SCID mice treated or not with Dex. Main data related to infected mice included in the study are shown in Table 1.

Dex induced a significant body weight loss in both Cryptosporidium infected and uninfected SCID mice $(P<0.001)$. In contrast, no significant body weight change was associated with parasite infection. Once infected with C. muris, mice from groups $M$ and MDex became chronic shedders and produced high numbers of oocysts without marked differences between the groups. On the other hand, in animals inoculated with C. parvum, the oocyst excretion was sporadic and limited in $\mathrm{P}$ mice, and high and chronic in PDex mice, with a statistically significant difference $(P=$ $0.002)$. Figure 1 shows the average of oocyst excretion in different groups of mice. Analysis of variance showed that the administration of Dex, Cryptosporidium species, and the interaction of these factors significantly influenced oocyst excretion (all the $P<0.001$ ). The level of oocyst excretion was higher in mice infected with $C$. muris than in those infected with C. parvum.

Pre-patent period ranged from 6 to 11 days (9.7 days in average) in $\mathrm{M}$ mice and it was 11 days for all MDex mice. Geometric means of oocyst excretion before sacrifice were 1839 and 1159 oocysts/mg faeces respectively (Table 1). At histological level, no difference between mice of groups $\mathrm{M}$ or MDex was observed. C. muris localization was restricted to the stomach, with no extra-gastric dissemination. Different stages of the parasite life cycle were present. 
Table I: Experimental infection of Dexamethasone-treated or untreated SCID mice infected with $C$. parvum or $C$. muris: Main clinical and histopathological data

\begin{tabular}{|c|c|c|c|c|c|}
\hline Groupa & Mouse $\mathrm{N}^{\circ}$ & $\begin{array}{l}\text { Day of euthanasia } \\
\text { (post-infection) }\end{array}$ & $\begin{array}{l}\text { Oocysts/mg faeces } \\
\text { at euthanasia }\end{array}$ & Clinical manifestations & Main histological changes \\
\hline \multirow[t]{6}{*}{$\mathbf{P}$} & I & 20 & 0 & Occasional diarrhoea & Undetected \\
\hline & 2 & 28 & 0 & Lethargy & Undetected \\
\hline & 3 & 28 & I & None & N.D. \\
\hline & 4 & 84 & I & Occasional diarrhoea & Undetected \\
\hline & 5 & 84 & 4 & Occasional diarrhoea & Undetected \\
\hline & 6 & 84 & 0 & Occasional diarrhoea & N.D. \\
\hline \multirow[t]{6}{*}{ Pdex } & 7 & 20 & 29 & Occasional diarrhoea & Undetected \\
\hline & 8 & 28 & 102 & Lethargy, ruffled coat & Undetected \\
\hline & 9 & 28 & 95 & Lethargy, ruffled coat & N.D. \\
\hline & 10 & 46 & 1182 & Lethargy, ruffled coat & $\begin{array}{l}\text { Polyps with areas of low-grade and high- } \\
\text { grade intraepithelial neoplasia, and } \\
\text { intramucosal adenocarcinoma at the } \\
\text { ileocaecal region }\end{array}$ \\
\hline & 11 & 62 & 240 & Lethargy, ruffled coat & $\begin{array}{l}\text { Polyps with areas of low-grade and high- } \\
\text { grade intraepithelial neoplasia, and } \\
\text { intramucosal adenocarcinoma at the } \\
\text { ileocaecal region }\end{array}$ \\
\hline & 12 & 84 & 695 & Lethargy, ruffled coat & $\begin{array}{c}\text { Polyps with areas of low-grade and high- } \\
\text { grade intraepithelial neoplasia, and } \\
\text { intramucosal adenocarcinoma at the } \\
\text { ileocaecal region }\end{array}$ \\
\hline \multirow[t]{6}{*}{$\mathbf{M}$} & 13 & 20 & 1078 & None & $\begin{array}{l}\text { Stomach heavily infected mainly at the } \\
\text { fundic region; dilated glands; hyperplasia }\end{array}$ \\
\hline & 14 & 20 & 407 & None & N.D. \\
\hline & 15 & 28 & 742 & None & $\begin{array}{l}\text { Stomach heavily infected mainly at the } \\
\text { fundic glands, hyperplasia }\end{array}$ \\
\hline & 16 & 84 & $4 \mid 43$ & None & $\begin{array}{l}\text { Stomach heavily infected mainly at the } \\
\text { fundic region; dilated glands; hyperplasia }\end{array}$ \\
\hline & 17 & 84 & 4920 & None & Stomach heavily infected \\
\hline & 18 & 84 & 5828 & None & None \\
\hline \multirow[t]{6}{*}{ Mdex } & 19 & 20 & 1538 & Occasional diarrhoea & Stomach heavily infected; dilated glands \\
\hline & 20 & 20 & 166 & Occasional diarrhoea & N.D. \\
\hline & 21 & 27 & 1241 & Occasional diarrhoea & N.D. \\
\hline & 22 & 32 & 4155 & $\begin{array}{l}\text { Frequent diarrhoea, lethargy, } \\
\text { ruffled coat }\end{array}$ & $\begin{array}{l}\text { Stomach heavily infected mainly at the } \\
\text { fundic glands; hyperplasia }\end{array}$ \\
\hline & 23 & 46 & 900 & Lethargy, ruffled coat & $\begin{array}{l}\text { Stomach heavily infected mainly at the } \\
\text { fundic glands; hyperplasia }\end{array}$ \\
\hline & 24 & 84 & 2051 & None & $\begin{array}{l}\text { Stomach heavily infected mainly at the } \\
\text { fundic glands; hyperplasia; a little } \\
\text { inflammation }\end{array}$ \\
\hline \multirow[t]{3}{*}{ C } & 25 & 20 & 0 & None & Undetected \\
\hline & 26 & 67 & 0 & Lethargy, ruffled coat & Undetected \\
\hline & 27 & 84 & 0 & None & Undetected \\
\hline \multirow[t]{3}{*}{ Cdex } & 28 & 20 & 0 & None & Undetected \\
\hline & 29 & 43 & 0 & None & Undetected \\
\hline & 30 & 84 & 0 & None & Undetected \\
\hline \multirow[t]{6}{*}{ Cdex 2} & 31 & 54 & 0 & None & Undetected \\
\hline & 32 & 54 & 0 & None & Undetected \\
\hline & 33 & 54 & 0 & None & Undetected \\
\hline & 34 & 54 & 0 & None & Undetected \\
\hline & 35 & 54 & 0 & None & Undetected \\
\hline & 36 & 54 & 0 & None & Undetected \\
\hline
\end{tabular}

aExperimental groups were:

P: C. parvum-infected SCID mice; PDex: C. parvum-infected Dex-treated SCID mice; M: C. muris-infected SCID mice; MDex: . muris-infected Dextreated SCID mice; C: Not infected SCID mice of control group inoculated with PBS; CDex: Not infected Dex-treated SCID mice of control group inoculated with PBS; CDex2: Not infected Dex-treated SCID mice that received an inoculum from which oocysts were previously removed by filtration; N.D.: Not done (These mice were not included in the histological examination). 


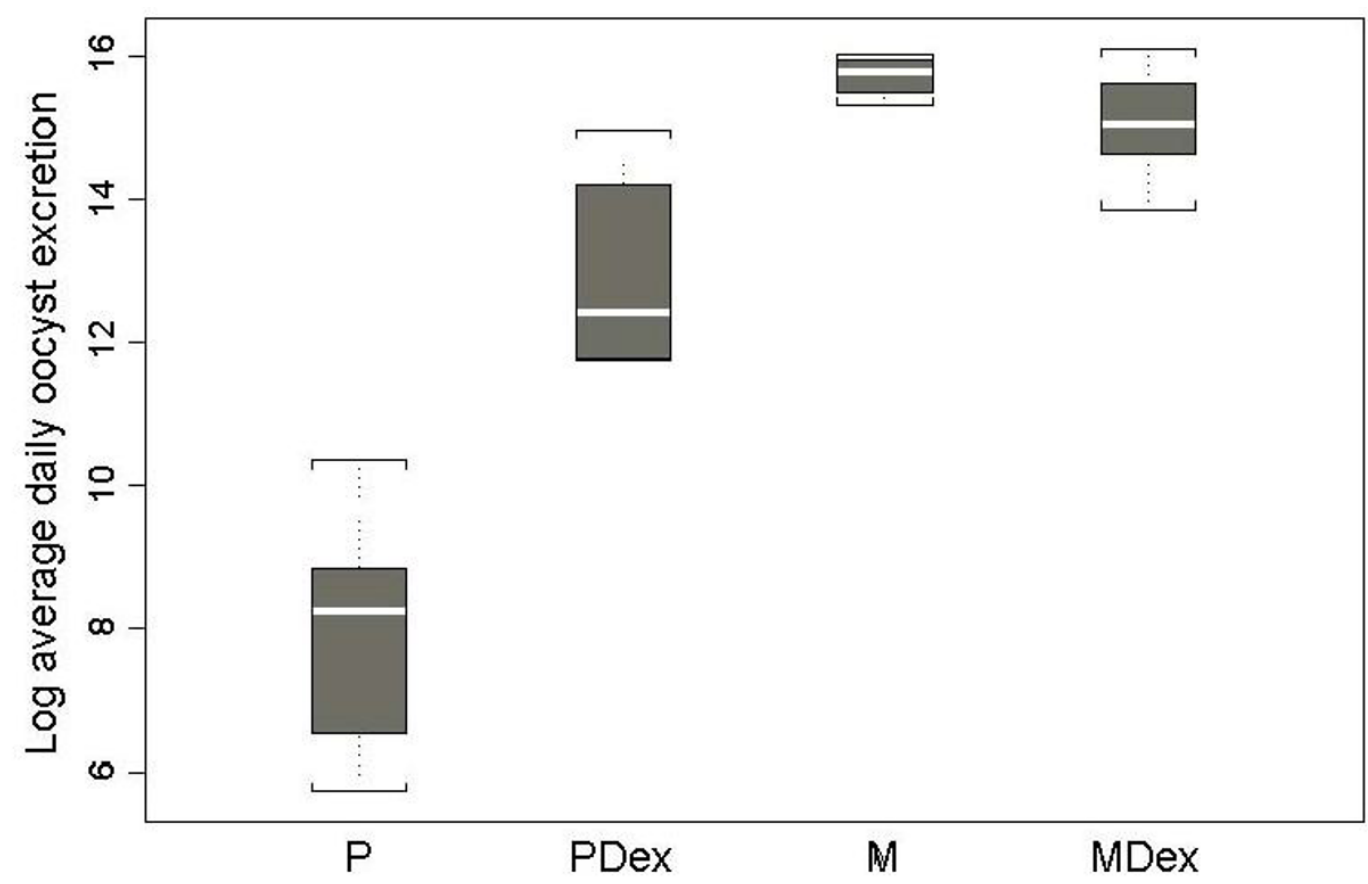

Figure I

Napierian logarithm of daily oocyst excretion (oocyst/mg faeces) in different groups of mice. Experimental groups were: P: $C$. parvum-infected SCID mice; PDex: $C$. parvum-infected Dex-treated SCID mice; M: $C$. muris-infected SCID mice; MDex: $C$. muris-infected Dex-treated SCID mice. Each box represents the middle half of data, the white line being the median. Whiskers represent the extreme values within I.5 times the box height.

Stomachs of all mice euthanatized at different dates, from day 20 to day 84 post-infection, were heavily infected mainly in fundic mucosae (Figure 2). Fundic gastric glands were dilated and covered by a flattened epithelium. Oxyntic cells were less numerous than in control mice and preferentially visible in the deeper area. Fundic mucosa was twice thinner than in control mice while pyloric mucosa was similar to that in uninfected control mice. A moderate inflammatory infiltrate, made of mononuclear cells and neutrophile polynuclears, was observed in some cases.

For C. parvum-infected SCID mice from group P, geometric mean of oocyst excretion before euthanasia was 1 oocyst/mg faeces. SCID mice from PDex group had a prepatent period ranging from 4 to 11 days (6.2 days in average) and developed a chronic infection. Geometric mean of oocyst excretion before sacrifice was 195 oocysts/mg of faeces for mice from group PDex. Two out of six PDex SCID mice were severely ill and required euthanasia. In mice infected with C. parvum, histopathological differences were revealed between Dex-treated and untreated animals. Untreated SCID mice infected with C. parvum have neither detectable parasites nor lesions at the histo- logical level (Figure 3) at any time during the course of the study.

In Dex-treated SCID mice infected with C. parvum, parasite localization was restricted to the gastrointestinal tract, mainly at the caecal region (Figure 3). Three out of five $(60 \%)$ histologically examined PDex SCID mice presented in the ileocaecal region polypoid, sessile, adenomatous masses, measuring approximately $2.5 \mathrm{~mm}$ in diameter. They appeared as closely packed, branching sometimes dilated tubular structures, separated by normal or inflammatory lamina propria. Focal cystic dilation was observed. Noticeably some tubules were covered by a low grade or high grade dysplastic epithelium, which showed mucin depletion and nuclear stratification. In some areas, architectural distortion was associated with marked cellular atypias (Figure 4). Epithelial cells presented a loss of their normal polarity. In addition, abnormal nuclear changes consisting of prominent nucleoli and irregularly scattered chromatin were observed (Figure 4). These mucosal changes were suggestive of intraepithelial neoplasia of low or high grade. In some areas, major cellular atypias, with foci of merged glands, typical of intramucosal adenocarcinoma, invasive into lamina propria, were found (Figures 4A and 4B). 

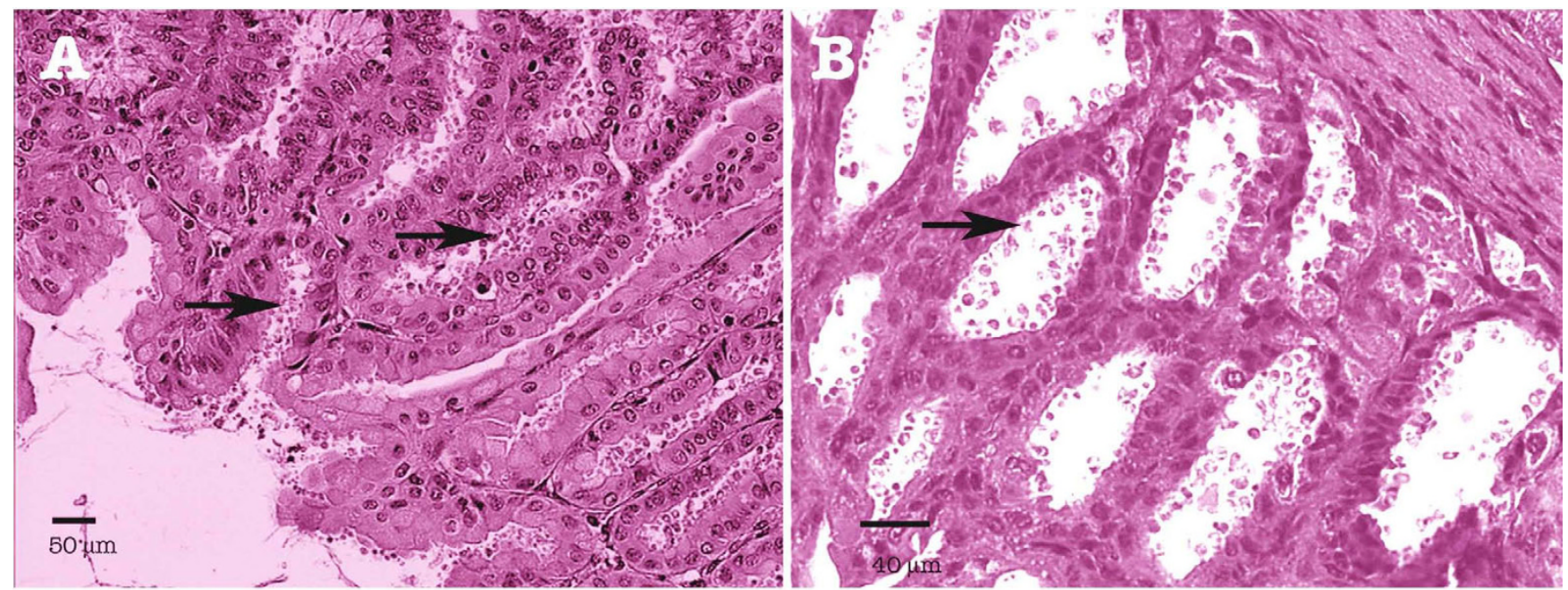

Figure 2

Experimental Cryptosporidium muris infection of SCID mice. (A) Stomach section from a Dex-untreated SCID mouse euthanatized at day 84 post-infection; (B) Stomach section from a Dex-treated SCID mouse euthanatized at day 46 post-infection. In both cases, gastric glands are filled with numerous parasites at different developmental stages (arrows). No signs of inflammation. Hematoxylin \& Eosin staining.

These major histological changes were earliest observed in one mouse euthanatized at day 46 post-infection and were found in all PDex mice necropsied after (Table 1). They were always associated with the presence of $C$. parvum organisms (Figures 4 and 5). In contrast, no parasite was detected in the stomach, duodenum, jejunum, hepatic biliary system or pancreas. The possibility that biotic (e.g. virus) or abiotic factors present in the inoculum could be responsible for these lesions was discarded by administering Dex-treated SCID mice with a filtered inoculum (i.e. without Cryptosporidium oocysts) (group Cdex2). Neither parasites in the faeces or tissues nor lesions were detected in these mice at any time of the experience.

\section{Discussion}

We developed a new animal model that allows a good propagation of two different species of Cryptosporidium. In this study, adult SCID mice treated with Dex became chronically infected with $10^{5}$ C. parvum or C. muris oocysts, and had a significant oocyst shedding during all the course of the experiments. Furthermore, this model was useful to compare C. muris and C. parvum infections at clinical, histopathological and parasitological levels.

In this study, variations in the expression of the disease in terms of either Cryptosporidium species or Dex administration were shown. Amounts of oocysts discharged seemed slightly lower in MDex than in M mice but this difference was not statistically significant. However, it appeared that the aggravation of the immunosuppression status did not lead to an increase in the severity of C. muris infection. Miller et al. previously reported that immunosuppressed mice were as or less susceptible to $C$. muris than immunocompetent mice [26]. However, this conclusion can hardly be extrapolated to all Cryptosporidium species, as long as in our experiments, the oocyst shedding was markedly and significantly higher in PDex than in P group. Further studies are required to determine minimal infectious dose, $\mathrm{ID}_{50}$ (infectious dose to 50 percent of exposed individuals) and other data for each species and according to the immunosuppression degree. Interestingly, data from very recent experiments with $C$. parvum confirmed the results of the present work (data not shown). The Dextreated SCID mouse model revealed therefore to be reproducible.

C. muris infection caused damage to the gastric mucosa of both mice from $\mathrm{M}$ and MDex groups. But though $\mathrm{M}$ mice were less ill than MDex mice, there was no marked histological difference between them. Dilated, hypertrophied and highly parasitized gastric glands without an extra gastric dissemination of parasites were the main histopathological changes. Additionally, a little inflammatory response was observed. Other authors have reported similar findings in relation with $C$. muris gastric infection $[12,27,28]$. However, to our knowledge, this is the first report of a clear preferential localization of the parasite colonization at the fundic level of the stomach, where acid secreting glands are numerous [29]. This could suggest a favourable influence of lower gastric $\mathrm{pH}$ on the growth of C. muris. 


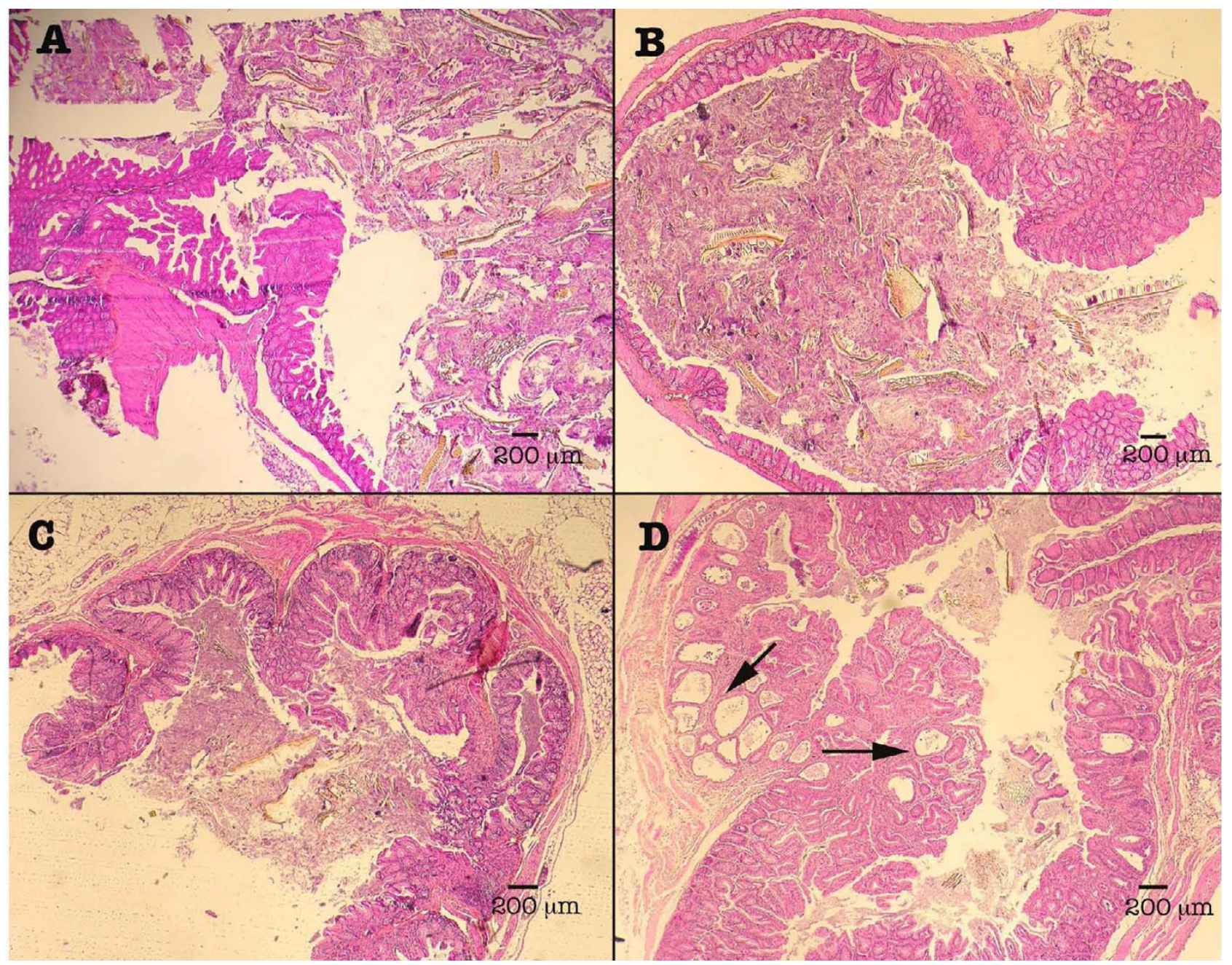

Figure 3

Ileocaecal regions of mice from different groups. Normal caecum of (A) Uninfected mouse administered with dexamethasone (CDex group), (B) C. muris-infected Dex-treated mouse (MD group) and (C) C. parvum-infected mouse (P group). (D) Projection of polypoid structures with focal cystic dilation (arrows) developing inside the intestinal lumen of a $C$. parvuminfected Dex-treated SCID mouse. Hematoxylin \& Eosin staining.

On the other hand, several studies using animal models have described histological changes in the intestinal epithelium due to C. parvum infection, such as villous atrophy and crypt hyperplasia in the lower small intestine [13] or in the caecum and the colon [12], cryptic hyperplasia with abscesation of crypts in the large intestine [13], stunting and fusion of villi, replacement of enterocytes by immature cells and eosinophilia of lamina propria [30], small and large intestine mucosa severely damaged with villous contraction and little or absent epithelial layer [31]. Another report described an association between Cryptosporidium sp. and aural-pharyngeal polyps in iguanas. These polyps were pedunculated masses composed of glandular cystic structures lined by hyperplastic cuboidal to columnar epithelium, containing numerous parasites along the apical surfaces of the epithelial cells [32]. Nevertheless, none of these studies have described the presence of carcinoma lesions associated to cryptosporidiosis. These lesions were first observed unexpectedly after 46 days post-infection, when the infection had become chronic, and were found only in C. parvum infected SCID mice treated with Dex. These findings were recorded using an inoculum relatively low ( $10^{5}$ oocysts) in comparison with the higher infectious doses, between $10^{6}$ and $10^{7}$, used by others $[12,33]$.

Several observations in our study suggest that combination of C. parvum with Dex administration is involved in the generation of these significant histological changes. Indeed, Dex seemed to be a critical factor to the develop- 


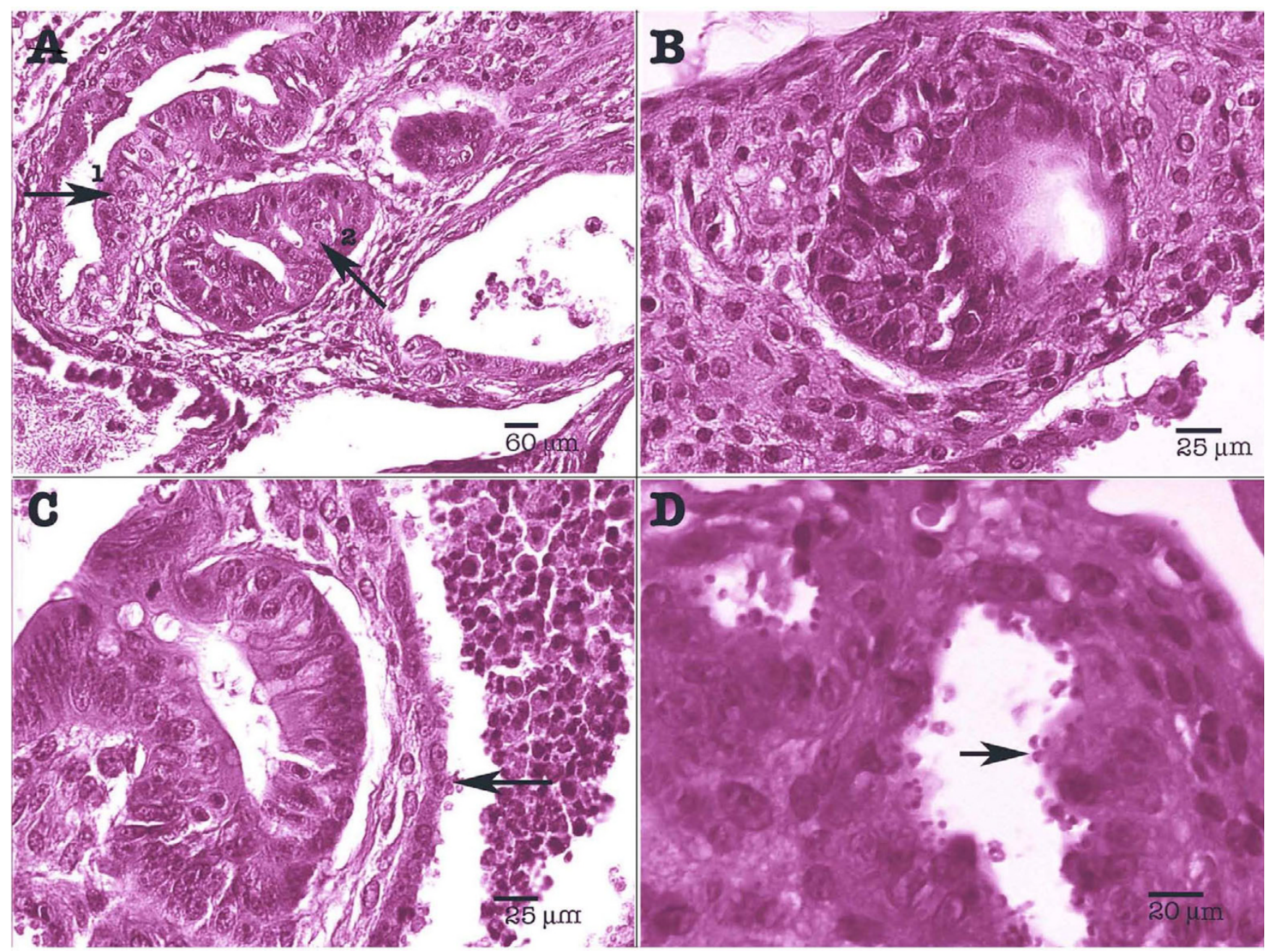

Figure 4

Experimental Cryptosporidium parvum infection of Dex-treated SCID mice: caecal region. (A) Polyp with areas of high-grade intraepithelial neoplasia (arrow I) and intramucosal adenocarcinoma (arrow 2); (B) Abnormal nuclear changes consisting of prominent nucleoli and irregularly scattered chromatin; (C) Highly irregular glands, areas of loss of glandular differentiation. Presence of numerous parasites (arrow); (D) Presence of numerous parasites at different developmental stages in the intestinal epithelium (arrow). Hematoxylin \& Eosin staining.

ment of intraepithelial adenocarcinoma in C. parvuminfected SCID mice. Dex potentially alters the innate immunity in C. parvum infected animals [23,24]. The higher oocyst shedding found in mice presenting these neoplasic lesions seems to confirm this assumption. Additionally, this kind of lesion was found neither in Dexuntreated $C$ parvum-infected animals with a low oocyst excretion during the course of the study, nor in the control Dex-treated non-infected group. A possible contamination of the inoculum with a virus or other agent potentially responsible for these neoplasic lesions was also discarded. Interestingly, C. muris was not able to induce this type of epithelial changes and the reasons of this different expression of the disease are unclear. It has been reported previously a variability in pathogenicity for different hosts between different Cryptosporidium species and types, suggesting the existence of specific virulence factors among species and isolates [34]. Further studies should be done to clarify this difference in pathogenicity. It is important to mention that these colonic neoplasic lesions are not listed among the typical background diseases due to the SCID mice genetic defect [35].

To our knowledge, this is the first time that C. parvum is associated with cancerogenesis. There is one case report that described cryptosporidiosis of the biliary tract clinically mimicking a pancreatic cancer in an AIDS patient [36]. However, biopsy of the gallbladder revealed crypt- 


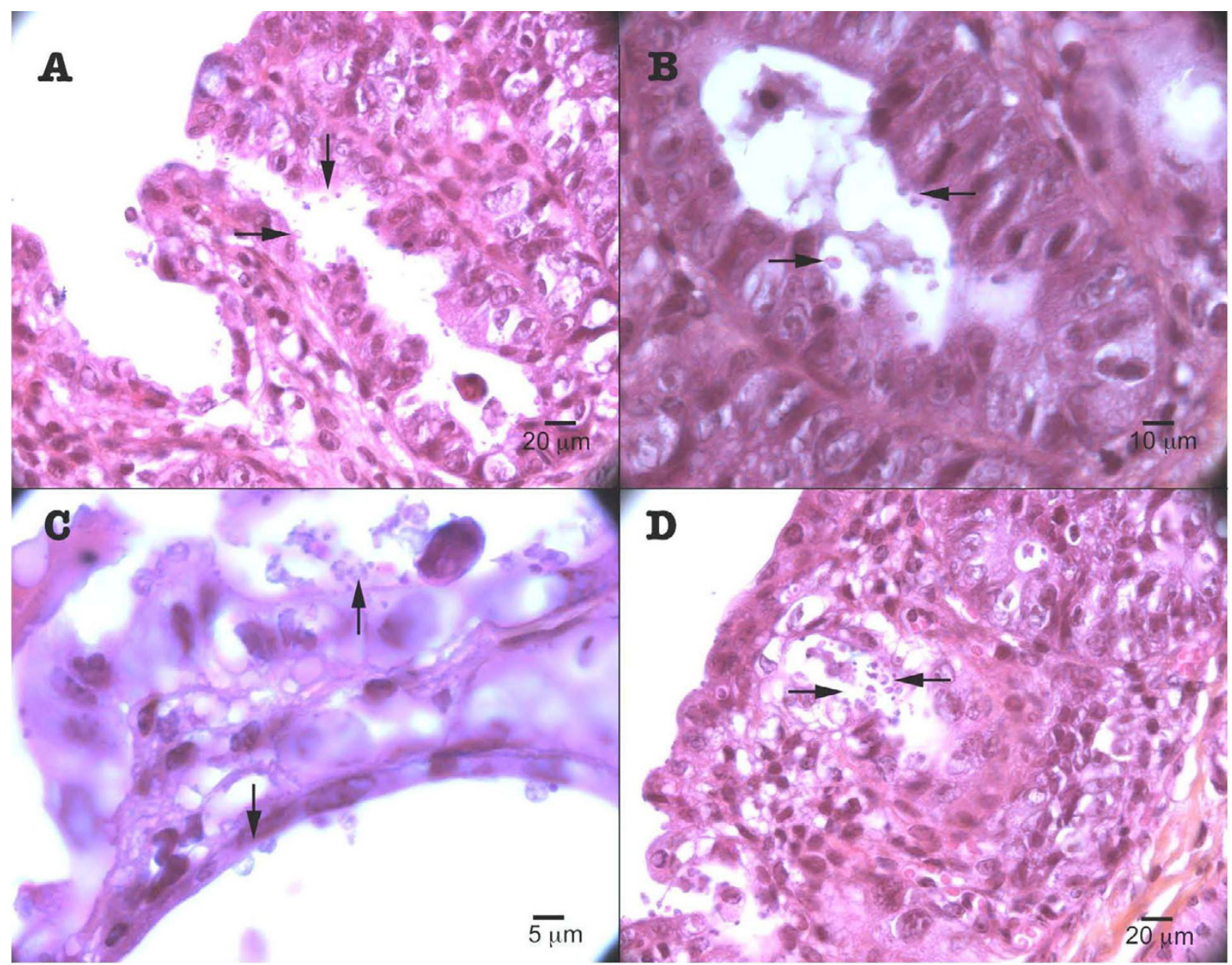

\section{Figure 5}

Experimental Cryptosporidium parvum infection of Dex-treated SCID mice. Low (A, D) and high magnification (B, C) of the caecal region showing the presence of abundant parasites (arrow), and high degree dysplasia (arrow). Hematoxylin \& Eosin staining.

osporidiosis causing inflammation of the biliary tract and ruled out the diagnosis of neoplasia [36]. Furthermore, a recent epidemiological study in Poland reported a high frequency of cryptosporidiosis in patients with colorectal cancer [37]. These data strengthen the interest of our experimental observations.

Several infectious agents, including parasites, have been linked to oncogenesis in humans. Some of these associations are strong. Particularly, Schistosoma hematobium has been described as a definitive cause of urinary bladder cancer by the International Agency for Research in Cancer. Also, a proportion of cholangiocarcinoma of the liver worldwide is attributable to Opisthorchiidae liver flukes [38]. Other associations still speculative with some protozoa were suggested on the basis of epidemiological obser- vations, such as Trichomona vaginalis and cervical cancer, or Toxoplasma gondii and tumors [39]. As well, a microbial pathogen such as Helicobacter pylori has been classified as oncogenic for humans due to its strong epidemiological association with carcinoma of stomach and gastric lymphoma $[38,40]$.

Because C. parvum is an opportunistic agent that causes significant morbidity and mortality in immunocompromised patients, it is possible that individuals infected with this parasite may have a higher risk of developing colorectal malignancies, especially when immunosuppression is more severe. In a retrospective study that shows the incidence and clinical course of colorectal malignancies in HIV/AIDS patients, adenocarcinoma was the type of cancer most frequently found among them. These patients 
did not have familial antecedents of intestinal malignancies or other risk factors, and developed tumors at earlier ages in comparison to immunocompetent persons [41]. Unfortunately, no data about gastro-intestinal parasites in these patients were given in the study [41]. More studies have to be done in humans to evaluate cryptosporidiosis as a possible risk factor of colorectal cancer.

Epidemiological studies have shown that environmental factors may play a role in colon cancer susceptibility [42]. The association between chronic inflammation and cancer is also well known [43]. Particularly, colon cancer has also been associated to inflammatory bowel disease. In the latter case, cancer develops after sustained gut inflammation. However, in the present work C. parvum infection was associated with only mild inflammation of the intestine as reported also by others [12].

Taking into consideration that the observations described herein were replicated in a second experiment (unpublished data), it can be concluded that C. parvum is able to induce the formation of polyps and carcinogenic lesions in the gut of Dex-treated SCID mice. However, more work has to be done to elucidate this interesting association and to further understand cryptosporidiosis pathogenesis.

\section{Conclusion}

In summary, for the first time C. parvum was associated with the generation of polyps and in situ adenocarcinoma in the gut of Dex-treated SCID mice. Additionally, we have developed a model to compare chronic muris and parvum cryptosporidiosis using SCID mice treated with corticoids. This reproducible model has allowed the evaluation of clinical impact, oocyst shedding, location of the infections, pathogenic power, and histopathological changes indicating divergent effects of Dex according to Cryptosporidium species.

\section{Methods}

\section{Cryptosporidium oocysts}

C. parvum IOWA and C. muris RN66 oocysts were purchased from Waterborne ${ }^{\mathrm{TM}}$, Inc. (New Orleans, Louisiana) and stored in shipping medium (Phosphate-buffered saline (PBS) with penicillin, streptomycin, gentamycin, amphotericin B and $0.01 \%$ Tween 20 ) at $4{ }^{\circ} \mathrm{C}$ until use. Oocyst viability before inoculation was determined by a trypsin-taurocholate excystation test [44] and absence of germs was assured by testing the oocyst suspensions on Plate Count Agar and on Sabouraud plates.

\section{Animals}

Nine week-old male and female CB17-SCID mice were obtained from a colony bred at the Pasteur Institute of Lille (France), and maintained under aseptic conditions in an isolator, with standard laboratory food for experi- mental mice and water ad libitum. All cages, food, water and bedding were sterilized before use. Faecal pellets were collected from all mice before inoculation to ascertain the absence of pre-existing Cryptosporidium infection. The conditions for the care of laboratory animals stipulated in European guidelines (Council directives on the protection of animals for experimental and other scientific purposes. J. Off. Communautés Européennes, 86/609/EEC, 1986, December $18^{\text {th }}$ L358) were followed.

\section{Immunosuppression}

When needed (see the next section), SCID mice were chemically immunosuppressed by administering $4 \mathrm{mg} / \mathrm{L}$ of dexamethasone sodium phosphate (Dex) (Merck, Lyon, France) via the drinking water. Immunosuppression was started two weeks prior to inoculation and was maintained during the whole experimentation. Dexadded water was replaced three times a week.

\section{Experimental design}

Twenty-four SCID mice, housed individually (onemouse-cage) in capped cages, were randomly divided into four groups: P, M, PDex and MDex, described hereinafter. Six SCID mice, housed by three, constituted two control groups, $\mathrm{C}$ and CDex. Oral inoculation was done with $10^{5}$ oocysts in $200 \mu \mathrm{l}$ of PBS. Six mice were infected with $C$. parvum oocysts (group P) and six others with C. muris oocysts (group M). Under the effect of Dex immunosuppression, six mice were infected with $C$. parvum oocysts (group PDex) and six others with C. muris oocysts (group MDex). Mice of control groups were inoculated only with PBS, without (group C) or with (group CDex) Dex administration. A further control group was constituted by six SCID mice that received an inoculum from which oocysts were previously removed by filtration with a Nanosep MF tube with a $0.45 \mu \mathrm{m}$ pore size membrane (group CDex2).

\section{Quantification of the oocyst shedding}

To evaluate the intensity of oocyst shedding over the course of Cryptosporidium infection, freshly excreted faecal pellets were collected three times a week from each mouse and suspended in MilliQ water. Oocysts were detected and numbered after staining faecal smears with modified Ziehl-Neelsen stain [45].

\section{Statistical analysis}

Analyses of data were performed with the statistical software S-PLUS 2000 (MathSoft, Seattle, WA, USA). For statistical analyse purposes, logarithmic transformations of oocyst excretion values were used. Wilcoxon rank sum tests were used to compare body weights or oocyst excretion. An analysis of variance was conducted to account for the effects of relevant factors and their interactions on average daily excretion of oocysts. An average amount of oocysts excreted per day was estimated for each mouse 
from all the unitary values, and was represented as a function of the mouse group in a Box \& Whiskers Plot.

\section{Histological examination}

Periodically or when signs of imminent death appeared, mice were euthanatized by a sodium pentobarbital (Ceva, Libourne, France) intra-cardiac injection. The liver, stomach and pancreas, a section of the duodenum, 3 sections of the jejunum, the caecum, and 3 sections of the colon were removed. Tissues were fixed in $10 \%$ neutral formalin and embedded in paraffin. Histological sections were stained with hematoxylin and eosin, and examined microscopically for the detection of Cryptosporidium organisms and/or histological modifications of the host tissue. Pathological changes found in the mouse caecum were classified according to the Vienna classification of tumors of the digestive system $[46,47]$.

\section{Competing interests}

The author(s) declare that they have no competing interests.

\section{Authors' contributions}

GC \& TN have equally contributed to this work. They participated in the conception and design of the study, carried out the experiments and drafted the manuscript. KG participated in the design of the experiments. NG, TC, AM participated in the performance of animal experiments. LF prepared the histological cuts. AP carried out the statistical analysis. JCC participated in the design of the study. ED participated in the design and coordination of the study and helped to draft the manuscript. CC carried out the pathological study and helped to draft the manuscript. All authors read and approved the final manuscript.

\section{Acknowledgements}

We would like to thank Dr. Magali Chabé, Prof. El Moukhtar Aliouat, Dr. Dominique Leprince for their valuable advices and support, Nicolas Flament and Florent Le Broc for technical assistance. Precious points of view of Dr. Stephanos Papadopulos and Prof. Pierre Gosset, pathologists, were very helpful for this work. This work received financial support from the Ministry of Research, France (EA3609), IFR I 42 (Institut Pasteur de Lille), GIS Lille Genopole. G.C. was supported by a scholarship from the Consejo de Desarrollo Científico y Humanístico of the Universidad Central de Venezuela. T.N. was supported by a French Ministry Research grant.

\section{References}

I. Caccio SM, Pozio E: Advances in the epidemiology, diagnosis and treatment of cryptosporidiosis. Expert Rev Anti Infect Ther 2006, 4:429-443.

2. Xiao L, Fayer R, Ryan U, Upton SJ: Cryptosporidium taxonomy: recent advances and implications for public health. Clin Microbiol Rev 2004, I 7:72-97.

3. Pozio E, Morales MA: The impact of HIV-protease inhibitors on opportunistic parasites. Trends Parasitol 2005, 2 I :58-63.

4. Sunnotel O, Lowery CJ, Moore JE, Dooley JS, Xiao L, Millar BC, Rooney PJ, Snelling WJ: Cryptosporidium. Lett Appl Microbiol 2006, 43:7-16.

5. Lopez-Velez R, Tarazona R, Garcia Camacho A, Gomez-Mampaso E, Guerrero A, Moreira V, Villanueva R: Intestinal and extraintesti- nal cryptosporidiosis in AIDS patients. Eur J Clin Microbiol Infect Dis 1995, 14:677-68I.

6. Chen XM, Levine SA, Splinter PL, Tietz PS, Ganong AL, Jobin C, Gores GJ, Paya CV, LaRusso NF: Cryptosporidium parvum activates nuclear factor kappaB in biliary epithelia preventing epithelial cell apoptosis. Gastroenterology 200 I, I 20: 1774- I783.

7. Mele R, Gomez Morales MA, Tosini F, Pozio E: Cryptosporidium parvum at different developmental stages modulates host cell apoptosis in vitro. Infect Immun 2004, 72:606I-6067.

8. Mallon M, MacLeod A, Wastling J, Smith H, Reilly B, Tait A: Population structures and the role of genetic exchange in the zoonotic pathogen Cryptosporidium parvum. J Mol Evol 2003, 56:407-417.

9. Alves M, Matos O, Antunes F: Microsatellite analysis of Cryptosporidium hominis and $\mathrm{C}$. parvum in Portugal: a preliminary study. J Eukaryot Microbiol 2003, 50 Suppl:529-530.

10. Tanriverdi S, Markovics A, Arslan MO, Itik A, Shkap V, Widmer G: Emergence of distinct genotypes of Cryptosporidium parvum in structured host populations. Appl Environ Microbiol 2006, 72:2507-25।3.

II. Ngouanesavanh T, Guyot K, Certad G, Fichoux YL, Chartier C, Verdier RI, Cailliez JC, Camus D, Dei-Cas E, Banuls AL: Cryptosporidium Population Genetics: Evidence of Clonality in Isolates from France and Haiti. J Eukaryot Microbiol 2006, 53:Suppl:S33-S36.

12. McDonald V, Deer R, Uni S, Iseki M, Bancroft G]: Immune responses to Cryptosporidium muris and Cryptosporidium parvum in adult immunocompetent or immunocompromised (nude and SCID) mice. Infect Immun 1992, 60:3325-333I.

13. Heine J, Moon HW, Woodmansee DB: Persistent Cryptosporidium infection in congenitally athymic (nude) mice. Infect Immun 1984, 43:856-859.

14. Iseki M, Maekawa T, Moriya K, Uni S, Takada S: Infectivity of Cryptosporidium muris (strain RN 66) in various laboratory animals. Parasitol Res 1989, 75:218-222.

15. Mead JR, Arrowood MJ, Sidwell RW, Healey MC: Chronic Cryptosporidium parvum infections in congenitally immunodeficient SCID and nude mice. J Infect Dis I99I, 163:1297-I304.

16. Petry F, Robinson HA, McDonald V: Murine infection model for maintenance and amplification of Cryptosporidium parvum oocysts. J Clin Microbiol 1995, 33: I922-1924.

17. Okhuysen PC, Rich SM, Chappell CL, Grimes KA, Widmer G, Feng $X$, Tzipori S: Infectivity of a Cryptosporidium parvum isolate of cervine origin for healthy adults and interferon-g knockout mice. J Infect Dis 2002, I 85: I 320-I 325.

18. Singh I, Theodos C, Li W, Tzipori S: Kinetics of Cryptosporidium parvum-specific cytokine responses in healing and nonhealing murine models of C. parvum infection. Parasitol Res 2005, 97:309-317.

19. Riggs MW: Recent advances in cryptosporidiosis: the immune response. Microbes Infect 2002, 4:1067-1080.

20. Seydel KB, Stanley SL Jr.: SCID mice and the study of parasitic disease. Clin Microbiol Rev 1996, 9:126-134.

21. Robinson P, Okhuysen PC, Chappell CL, Lewis DE, Shahab I, Lahoti S, White AC Jr.: Expression of IL-I5 and IL-4 in IFN-gammaindependent control of experimental human Cryptosporidium parvum infection. Cytokine 200I, I5:39-46.

22. Pollok RC, Farthing MJ, Bajaj-Elliott M, Sanderson IR, McDonald V: Interferon gamma induces enterocyte resistance against infection by the intracellular pathogen Cryptosporidium parvum. Gastroenterology 2001, 120:99-107.

23. Franchimont $D$ : Overview of the actions of glucocorticoids on the immune response: a good model to characterize new pathways of immunosuppression for new treatment strategies. Ann N Y Acad Sci 2004, 1024: 124-I 37.

24. Stojadinovic O, Lee B, Vouthounis C, Vukelic S, Pastar I, Blumenberg $M$, Brem $H$, Tomic-Canic M: Novel genomic effects of glucocorticoids in epidermal keratinocytes: inhibition of apoptosis, interferon-gamma pathway, and wound healing along with promotion of terminal differentiation. I Biol Chem 2007, 282:402I-4034

25. Chabé M, Dei-Cas E, Creusy C, Fleurisse L, Respaldiza N, Camus D, Durand-joly I: Immunocompetent hosts as a reservoir of Pneumocystis organisms: histological and rt-PCR data demonstrate active replication. Eur J Clin Microbiol Infect Dis 2004, 23:89-97. 
26. Miller TA, Ware MW, Wymer LJ, Schaefer FW 3rd: Chemically and genetically immunocompromised mice are not more susceptible than immunocompetent mice to infection with Cryptosporidium muris. Vet Parasitol 2007, I43:99-105.

27. Taylor MA, Marshall RN, Green JA, Catchpole J: The pathogenesis of experimental infections of Cryptosporidium muris (strain RN 66) in outbred nude mice. Vet Parasitol 1999, 86:4I-48.

28. Miller TA, Schaefer FW 3rd: Characterization of a Cryptosporidium muris infection and reinfection in CF-I mice. Vet Parasitol 2007, 144:208-22I.

29. Soybel DI: Anatomy and physiology of the stomach. Surg Clin North Am 2005, 85:875-94, v.

30. Enemark HL, Bille-Hansen V, Lind P, Heegaard PM, Vigre H, Ahrens $\mathrm{P}$, Thamsborg SM: Pathogenicity of Cryptosporidium parvum-evaluation of an animal infection model. Vet Parasitol 2003, I 1 3:35-57.

31. Tzipori S, Rand W, Griffiths J, Widmer G, Crabb J: Evaluation of an animal model system for cryptosporidiosis: therapeutic efficacy of paromomycin and hyperimmune bovine colostrumimmunoglobulin. Clin Diagn Lab Immunol 1994, I:450-463.

32. Uhl EW, Jacobson E, Bartick TE, Micinilio J, Schimdt R: Aural-pharyngeal polyps associated with Cryptosporidium infection in three iguanas (Iguana iguana). Vet Pathol 200I, 38:239-242.

33. Mead JR, Ilksoy N, You X, Belenkaya Y, Arrowood MJ, Fallon MT, Schinazi RF: Infection dynamics and clinical features of cryptosporidiosis in SCID mice. Infect Immun 1994, 62:169|-1695.

34. Okhuysen PC, Chappell CL: Cryptosporidium virulence determinants--are we there yet? Int J Parasitol 2002, 32:5 17-525.

35. Sundberg JP, Shultz LD: The Severe Combined Immunodeficiency (scid) Mutation. JAX NOTES 1993, 453:

36. de Souza Ldo R, Rodrigues MA, Morceli J, Kemp R, Mendes RP: Cryptosporidiosis of the biliary tract mimicking pancreatic cancer in an AIDS patient. Rev Soc Bras Med Trop 2004, 37:182-185.

37. Sulzyc-Bielicka V, Kuzna-Grygiel W, Kolodziejczyk L, Bielicki D, Kladny J, Stepien-Korzonek M, Telatynska-Smieszek B: Cryptosporidiosis in patients with colorectal cancer. J Parasitol 2007, 93:722-724.

38. Parkin DM: The global health burden of infection-associated cancers in the year 2002. Int I Cancer 2006, I I 8:3030-3044.

39. Khurana S, Dubey ML, Malla N: Association of parasitic infections and cancers. Indian I Med Microbiol 2005, 23:74-79.

40. Fox JG, Wang TC: Inflammation, atrophy, and gastric cancer. J Clin Invest 2007, I I 7:60-69.

4I. Yeguez JF, Martinez SA, Sands DR, Sands LR, Hellinger MD: Colorectal malignancies in HIV-positive patients. Am Surg 2003, 69:981-987.

42. Heyer J, Yang K, Lipkin M, Edelmann W, Kucherlapati R: Mouse models for colorectal cancer. Oncogene 1999, 18:5325-5333.

43. Taketo MM: Mouse models of gastrointestinal tumors. Cancer Sci 2006, 97:355-36I.

44. Guyot K, Gireaudot-Liepmann MF, Cabon A, Riveau-Ricard I, Lange M, Delattre JM, Dei-Cas E: Influence Of US Epa 1622 Method Successive Steps On The Viability Of Cryptosporidium Oocysts. Water Science \& Technology 2000, 4 1:189-196.

45. Henriksen SA, Pohlenz JF: Staining of cryptosporidia by a modified Ziehl-Neelsen technique. Acta Vet Scand I98I, 22:594-596.

46. Hamilton SR, Aalfonen LA, eds.: Pathology and Genetics.Tumours of the Digestive System. WHO classification of tumours. Lyon, IARC Press; 2000:III.

47. Stolte M: The new Vienna classification of epithelial neoplasia of the gastrointestinal tract: advantages and disadvantages. Virchows Arch 2003, 442:99-106.

Publish with BioMed Central and every
scientist can read your work free of charge
"BioMed Central will be the most significant development for
disseminating the results of biomedical research in our lifetime. "
Sir Paul Nurse, Cancer Research UK
Your research papers will be:
- available free of charge to the entire biomedical community
- peer reviewed and published immediately upon acceptance
- cited in PubMed and archived on PubMed Central
• yours - you keep the copyright
Submit your manuscript here:
http://www.biomedcentral.com/info/publishing_adv.asp

